\title{
Clostridium difficile colonization in preoperative colorectal cancer patients
}

\author{
Yi Zheng ${ }^{1, *}$, Yun Luo ${ }^{2, *}$, Yinxiang Lv ${ }^{3}$, Chen Huang ${ }^{2}$, Qinsong Sheng ${ }^{4}$, Peng Zhao ${ }^{1}$, \\ Julian $\mathrm{Ye}^{2}$, Weiqin Jiang ${ }^{1}$, Lulu Liu ${ }^{1}$, Xiaojun Song ${ }^{2}$, Zhou Tong ${ }^{1}$, Wenbin Chen ${ }^{4}$, \\ Jianjiang Lin ${ }^{4}$, Yi-Wei Tang ${ }^{5}$, Dazhi Jin², Weijia Fang ${ }^{1}$ \\ ${ }^{1}$ Cancer Biotherapy Center, First Affiliated Hospital, School of Medicine, Zhejiang University, Hangzhou, China \\ ${ }^{2}$ Department of Microbiology, Zhejiang Provincial Center for Disease Control and Prevention, Hangzhou, China \\ ${ }^{3}$ Xinchang People's Hospital, Shaoxing, China \\ ${ }^{4}$ Department of Colorectal Surgery, First Affiliated Hospital, School of Medicine, Zhejiang University, Hangzhou, China \\ ${ }^{5}$ Department of Laboratory Medicine, Memorial Sloan Kettering Cancer Center; Department of Pathology and Medicine, Weill \\ Medical College of Cornell University, New York, NY, USA \\ *These authors have contributed equally to this work \\ Correspondence to: Dazhi Jin, email: dzjin@cdc.zj.cn \\ Weijia Fang, email: weijiafang@zju.edu.cn \\ Keywords: Clostridium difficile, colorectal cancer, colonization, epidemiology, transmission \\ Received: November 02, $2016 \quad$ Accepted: December 20, $2016 \quad$ Published: January 02, 2017
}

\section{ABSTRACT}

The entire process of Clostridium difficile colonization to infection develops in large intestine. However, the real colonization pattern of $\boldsymbol{C}$. difficile in preoperative colorectal cancer patients has not been studied. In this study, $33 \mathrm{C}$. difficile strains (16.1\%) were isolated from stool samples of 205 preoperative colorectal cancer patients. $C$. difficile colonization rates in lymph node metastasis patients $(22.3 \%)$ were significantly higher than lymph node negative patients $(10.8 \%)(O R=2.314$, $95 \% \mathrm{CI}=1.023-5.235, P=0.025)$. Meanwhile, patients positive for stool occult blood had lower $C$. difficile colonization rates than negative patients $(11.5 \%$ vs. $24.0 \%$, $\mathrm{OR}=0.300,95 \% \mathrm{CI}=0.131-0.685, P=0.019)$. A total of 16 sequence types were revealed by multilocus sequence typing. Minimum spanning tree and time-space cluster analysis indicated that all $C$. difficile isolates were epidemiologically unrelated. Antibiotic susceptibility testing showed all isolates were susceptible to vancomycin and metronidazole. The results suggested that the prevalence of $\boldsymbol{C}$. difficile colonization is high in preoperative colorectal cancer patients, and the colonization is not acquired in the hospital. Since lymph node metastasis colorectal cancer patients inevitably require adjuvant chemotherapy and $C$. difficile infection may halt the ongoing treatment, the call for sustained monitoring of $\boldsymbol{C}$. difficile in those patients is apparently urgent.

\section{INTRODUCTION}

Clostridium difficile infection (CDI) is one of the leading causes of antibiotic-associated diarrhea. Worldwidely, the incidence of CDI has increased significantly since ribotype 027 strains appeared at the beginning of the century. There have been a lot of outbreaks with severe cases reported in the United States and Europe. A recent study indicated that approximately 453,000 cases of CDI and 29,000 deaths associated with CDI were identified each year in the United States [1]. The risk factors of CDI include antibiotic exposure, advanced age and hospitalization, which have been reported in detail and widely accepted [2-5]. Cancer patients who were immunocompromised were reported to have a higher risk for CDI compared with non-cancer patients. It is due of antibiotic-like activity of several chemotherapy drugs and chemotherapy-induced neutropenia $[6,7]$.

C. difficile mainly colonizes the large bowel as a part of normal intestinal flora. There are toxigenic and nontoxigenic strains. Toxigenic strains release exotoxins TcdA and $\mathrm{TcdB}$ to result in colitis and other diseases. Prevalence of $C$. difficile colonization for ICU patients [8], cancer patients $[9,10]$, patients undergoing hematopoietic stem 
cell transplantation $[11,12]$, residents in long-term care facilities [13], and healthy people [14] has been previously reported. The rates of $C$. difficile colonization in adult patients are different in different regions, but significantly lower than those in children [15]. A substantial proportion of individuals in the asymptomatic population with $C$. difficile colonization have been demonstrated to serve as reservoirs for CDI [16]. Although the carriage of nontoxigenic $C$. difficile strains might prevent $\mathrm{CDI}$ in humans, toxigenic $C$. difficile colonization is regarded as an independent risk factor prone to developing CDI subsequently [15]. The risk factors of $C$. difficile colonization include previous hospitalization [9, 15, 17], previous exposure to antibiotics [15], the use of gastric acid-suppressing drugs [18], and host variables [8-15].

The intestinal microbiota is also believed to be directly involved in colorectal carcinogenesis [19]. However, the rate of $C$. difficile colonization in preoperative colorectal cancer (CRC) patients has not been previously reported. The main transmission pattern and specific risk factors of $C$. difficile colonization in hospitalized CRC patients remains unclear.

Here we performed a preliminary study to investigate the pattern of $C$. difficile colonization in preoperative CRC patients admitted in a tertiary teaching hospital in China. The aim of this study is to reveal the rate of $C$. difficile colonization and its correlation to clinical characteristics in preoperative $\mathrm{CRC}$ patients. In addition, genotypes and antibiotic resistance profiles of $C$. difficile strains in those patients were also analyzed.

\section{RESULTS}

\section{Collection of $C$. difficile isolates}

A total of 205 preoperative CRC patients were included in this study. Among them, Thirty-three (16.1\%) were positive for $C$. difficile. Among these thirty-three $C$. difficile isolates, twenty-eight $(84.8 \%)$ were positive for both $t c d \mathrm{~A}$ and $t c d \mathrm{~B}\left(\mathrm{~A}^{+} \mathrm{B}^{+}\right)$, four $(12.1 \%)$ were negative for $t c d \mathrm{~A}$ and positive for $t c d \mathrm{~B}\left(\mathrm{~A}^{-} \mathrm{B}^{+}\right)$, and one isolate $(3.0 \%)$ was non-toxigenic with neither $t c d \mathrm{~A}$ nor $t c d \mathrm{~B}\left(\mathrm{~A}^{-}\right.$ $\left.\mathrm{B}^{-}\right)$. Toxigenic isolates were dominant at a rate of $97.0 \%$. There was only one type of $C$. difficile isolate detected in each culture-positive stool specimen.

\section{Clinical characteristics of CRC patients and C. difficile colonization}

There were $134(65.4 \%)$ male and 71 (34.6\%) female patients. $C$. difficile colonization rate in male patients was $15.7 \%$, whereas in female patients was $16.9 \%(P=0.820)$. The mean age is 63.3 years old. The mean ages of the toxigenic $C$. difficile positive and $C$. difficile negative patients were 64.1 and 62.2 years old, respectively. As shown in Table 1, there is a tendency of higher $C$. difficile colonization rate in patients over 60 years old $(P=0.249)$. Among all CRC patients, 29 of the $173(16.8 \%)$ left-sided CRC patients were positive for C. difficile, and 4 of 32 (12.5\%) right-sided CRC patients were positive for $C$. difficile $(P=0.547)$, no colonization preference was found between different sides.

Pathological features including cancer sites of origin (colon to rectum), macroscopic morphology (exophytic to ulcerative), and differentiation (well to poor) of the CRC patients were then analyzed for correlation with $C$. difficile colonization. However, as shown in Table 1, no clear correlation was identified between the rate of colonization and these pathological features. In addition, whether the $\mathrm{CRC}$ patients are more prone to toxigenic or non-toxigenic C. difficile colonization is also inconclusive (data not shown).

Generally speaking, T4 (tumor penetrate the visceral peritoneum) and lymph node (LN) metastasis are of great importance for CRC patients as poor prognostic factors and indicators for adjuvant chemotherapy. While in terms of $C$. difficile colonization in CRC patients at different stages, a comparative analysis of rate of colonization between T4 and non-T4, LN metastasis and LN negative patients was performed. Interestingly, CRC patents with high risk factors are likely to have higher $C$. difficile colonization rate than others, as shown in Table 1. It is particularly true that patients of positive LN metastasis bear significantly higher rate of $C$. difficile colonization than those of negative LN $(22.3 \%$ to $10.8 \%, P=0.025)$. Multivariate logistic regression analysis also showed that $\mathrm{LN}$ metastasis is an independent risk factor for $C$. difficile colonization in CRC patients $(P=0.044)$.

CRC frequently causes chronic bleeding, inducing anemia and malnutrition. Therefore, stool OB and blood hemoglobin of the CRC patients were used as differential tools in correlation with $C$. difficile colonization. Among all 205 CRC patients studied, OB negative patients had significantly higher $C$. difficile positive rate than $\mathrm{OB}$ positive patients $(24.0 \%$ to $11.5 \%, P=0.019)$. Multivariate logistic regression analysis also revealed $\mathrm{OB}$ negativity as an independent predictor for $C$. difficile colonization ( $P=0.004)$. No relationship was found between blood hemoglobin level and $C$. difficile colonization. Nutritional indexes and metabolic profiles of CRC patients, include albumin, fast blood glucose, triglyceride, total cholesterol, high density lipoprotein, and body mass index, were collected and analyzed for possible relation to $C$. difficile colonization. However, as shown in Table 1, the results revealed that none of the indexes could be interpreted as risk factor for $C$. difficile colonization in CRC patients.

In addition, whether $C$. difficile colonization has effected the duration of hospitalization was also studied. For the $172 \mathrm{C}$. difficile negative patients, the average days in hospital were $15.4 \pm 0.34$ days (mean \pm s.e.m.), while the average days in hospital were $15.0 \pm 0.98$ days (mean \pm s.e.m.) for the $C$. difficile positive patients, the result was of no statistical difference $(P>0.05)$. 
Table 1: Characteristics and risk factors of $C$. difficile colonization in 205 CRC patients

\begin{tabular}{|c|c|c|c|c|c|c|c|}
\hline \multirow[t]{3}{*}{ Characteristic } & & \multicolumn{2}{|c|}{$\begin{array}{c}\text { No.(\%) of patients for } C \text {. } \\
\text { difficile status }\end{array}$} & \multicolumn{4}{|c|}{ Results for analysis } \\
\hline & & \multirow{2}{*}{$\begin{array}{c}\text { C. difficile } \\
\text { positive } \\
(\mathrm{n}=33)\end{array}$} & \multirow{2}{*}{$\begin{array}{c}\text { C. difficile } \\
\text { negative } \\
(\mathrm{n}=172)\end{array}$} & \multirow{2}{*}{$\begin{array}{c}\text { Bivariant } \\
P \text { value }\end{array}$} & \multicolumn{3}{|c|}{ Multivariant logistic } \\
\hline & & & & & OR & $95 \%$ CI & $P$ value \\
\hline \multirow[t]{2}{*}{ Age } & $<60(\mathrm{n}=74)$ & $9(12.2)$ & $65(87.8)$ & 0.249 & 1.560 & $0.652-3.735$ & 0.318 \\
\hline & $\geq 60(\mathrm{n}=131)$ & $24(18.3)$ & $107(81.7)$ & & & & \\
\hline \multirow[t]{2}{*}{ Site } & Colon $(n=91)$ & $15(16.5)$ & $76(83.5)$ & 0.893 & 0.991 & $0.397-2.474$ & 0.984 \\
\hline & Rectum $(n=114)$ & $18(15.8)$ & $96(84.2)$ & & & & \\
\hline \multirow[t]{2}{*}{ Morphology } & $\begin{array}{l}\text { Ulcerative } \\
(\mathrm{n}=134)\end{array}$ & $25(18.7)$ & $109(81.3)$ & 0.171 & 0.744 & $0.287-1.926$ & 0.242 \\
\hline & $\begin{array}{l}\text { Exophytic } \\
\quad(\mathrm{n}=71)\end{array}$ & $8(11.3)$ & $63(88.7)$ & & & & \\
\hline \multirow[t]{2}{*}{ Differentiation } & Poor $(n=62)$ & $8(12.9)$ & $54(87.1)$ & 0.413 & 1.424 & $0.825-6.481$ & 0.401 \\
\hline & Well $(n=143)$ & $25(17.5)$ & $118(82.5)$ & & & & \\
\hline \multirow[t]{2}{*}{ T stage } & Non-T4 $(n=150)$ & $20(13.3)$ & $130(86.7)$ & 0.075 & 2.301 & $0.963-5.500$ & 0.061 \\
\hline & $\mathrm{T} 4(\mathrm{n}=55)$ & $13(23.6)$ & $42(76.4)$ & & & & \\
\hline \multirow[t]{2}{*}{$\mathrm{N}$ stage } & LN neg. $(n=111)$ & $12(10.8)$ & $99(89.2)$ & $0.025^{*}$ & 2.314 & $1.023-5.235$ & $0.044^{*}$ \\
\hline & LN pos. $(\mathrm{n}=94)$ & $21(22.3)$ & $73(77.7)$ & & & & \\
\hline \multirow[t]{2}{*}{ Albumin $(\mathrm{g} / \mathrm{L})$} & $<35(\mathrm{n}=17)$ & $5(29.4)$ & $12(70.6)$ & 0.119 & 0.315 & $0.073-1.357$ & 0.121 \\
\hline & $\geq 35(\mathrm{n}=188)$ & $28(14.9)$ & $160(85.1)$ & & & & \\
\hline \multirow[t]{2}{*}{$\mathrm{FBG}(\mathrm{mmol} / \mathrm{L})$} & $<7.0(\mathrm{n}=192)$ & $32(16.7)$ & $160(83.3)$ & 0.394 & 0.337 & $0.033-3.455$ & 0.360 \\
\hline & $\geq 7.0(\mathrm{n}=13)$ & $1(7.7)$ & $12(92.3)$ & & & & \\
\hline \multirow[t]{2}{*}{ BMI } & $<24(\mathrm{n}=114)$ & $17(14.9)$ & $97(85.1)$ & 0.605 & 1.358 & $0.581-3.177$ & 0.480 \\
\hline & $\geq 24(\mathrm{n}=91)$ & $16(17.6)$ & $75(82.4)$ & & & & \\
\hline \multirow[t]{2}{*}{$\mathrm{TG}(\mathrm{mmol} / \mathrm{L})$} & $\geq 1.70(\mathrm{n}=38)$ & $6(15.8)$ & $32(84.2)$ & 0.954 & 1.129 & $0.497-4.703$ & 0.917 \\
\hline & $<1.70(\mathrm{n}=167)$ & $27(16.2)$ & $140(83.8)$ & & & & \\
\hline \multirow[t]{2}{*}{$\mathrm{TC}(\mathrm{mmol} / \mathrm{L})$} & $<5.70(\mathrm{n}=190)$ & $31(16.3)$ & $159(83.7)$ & 0.762 & 0.858 & $0.097-3.199$ & 0.612 \\
\hline & $\geq 5.70(\mathrm{n}=15)$ & $2(13.3)$ & $13(86.7)$ & & & & \\
\hline \multirow[t]{2}{*}{$\mathrm{HDL}(\mathrm{mmol} / \mathrm{L})$} & $<0.80(\mathrm{n}=20)$ & $2(10.0)$ & $18(90.0)$ & 0.435 & 1.768 & $0.337-9.274$ & 0.500 \\
\hline & $\geq 0.80(\mathrm{n}=185)$ & $31(16.8)$ & $154(83.2)$ & & & & \\
\hline \multirow[t]{2}{*}{$\begin{array}{l}\text { Hemoglobin } \\
(\mathrm{g} / \mathrm{L})\end{array}$} & $<120(\mathrm{n}=55)$ & $10(18.2)$ & $45(81.8)$ & 0.623 & 0.911 & $0.319-2.602$ & 0.861 \\
\hline & $\geq 120(\mathrm{n}=150)$ & $23(15.3)$ & $127(84.7)$ & & & & \\
\hline \multirow[t]{2}{*}{ OB } & Negative $(n=75)$ & $18(24.0)$ & $57(76.0)$ & $0.019^{*}$ & 0.300 & $0.131-0.685$ & $0.004^{*}$ \\
\hline & Positive $(n=130)$ & $15(11.5)$ & $115(88.5)$ & & & & \\
\hline
\end{tabular}

Abbreviations: ${ }^{*} P<0.05$; LN: Lymph nodes; FBG: Fast blood glucose; BMI: Body mass index; TG: Triglyceride; TC: Total cholesterol; HDL: High density lipoprotein 


\section{Molecular typing of $C$. difficile isolates from CRC patients}

MLST results divided the $33 \mathrm{C}$. difficile isolates into $16 \mathrm{STs}$, indicating a great diversity of the genotype of $C$. difficile colonization. As previously described, three toxin gene profiles were included labeled as $\mathrm{A}^{+} \mathrm{B}^{+}$, $\mathrm{A}^{-} \mathrm{B}^{+}$, and $\mathrm{A}^{-} \mathrm{B}^{-}$. ST35 (21.2\%) was predominant which consists of 7 isolates. A minimum spanning tree was constructed (Figure 1). The eBURST analysis showed none of a single ST formed a clonal complex. Four sets of closely related STs are listed as the follows. ST37 and ST39 are in the same set, ST17, ST98, ST54 and
ST35 consists of one set, ST102, ST14, ST205, ST2 and ST26 with genetic relevance belongs to one set, and the remaining STs belongs to another set. The temporospatial relationship for same STs was mapped over the study period as shown in Figure 2. No cluster of any ST was observed. There were no overlaps among these cases in each ST line in time and space. These results indicate that no cases of the 33 isolates were genetic or epidemiological related. Although all the 33 patients finally had hospital stays varies from one week to less than four weeks, they did not obviously get infected with $C$. difficile during the time of hospitalization.

\section{9}
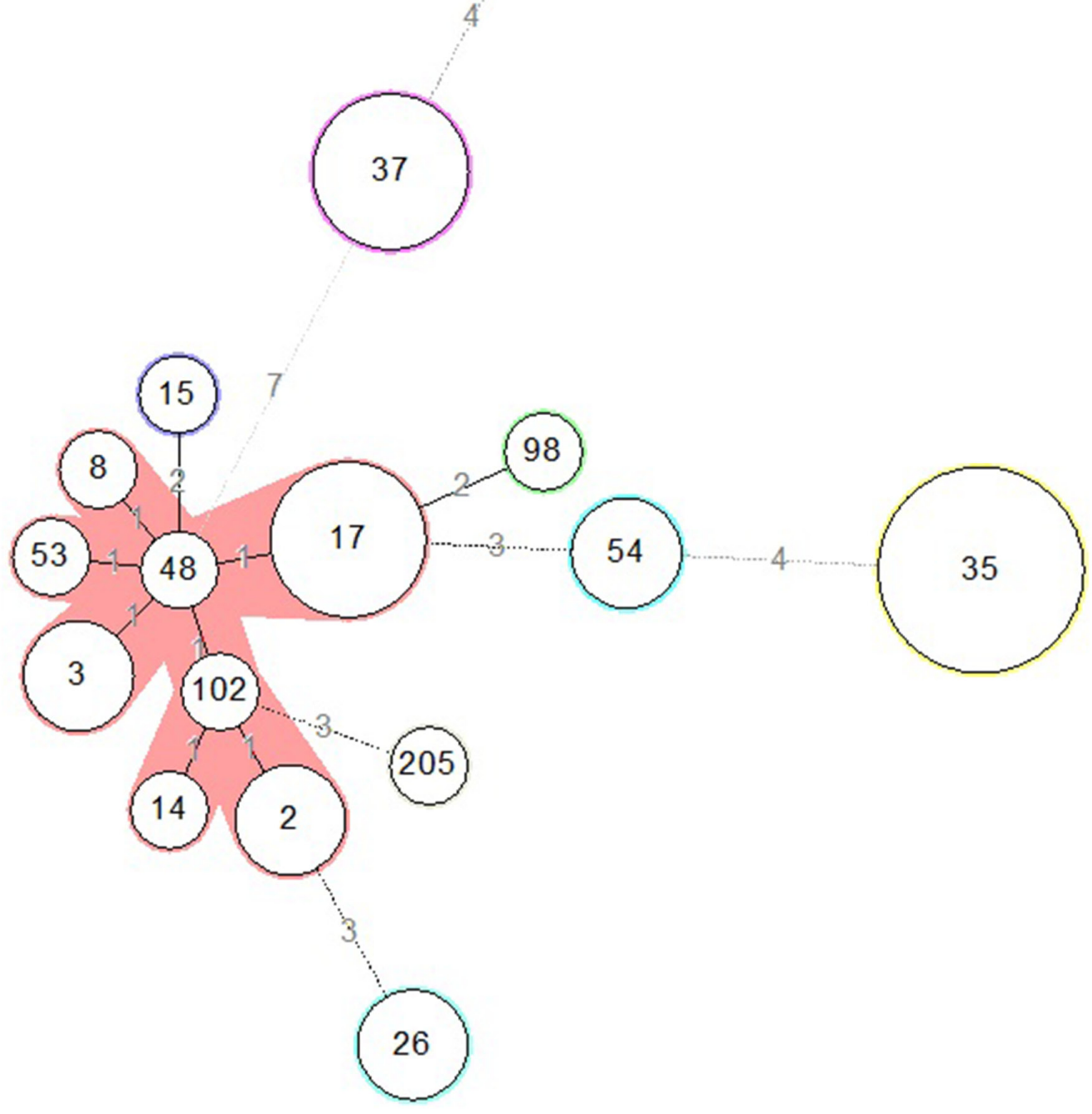

Figure 1: Relationships of the 33 colonizing $C$. difficile strains by minimum spanning tree based on MLST data. The number in the circle indicates the ST and the size of the circle corresponds the total number of isolates belonging to that ST. The number of allelic difference between STs is indicated on the branches. Nodes were connected by a dashed line if the difference is more than two alleles. 


\section{Antimicrobial resistance of $C$. difficile isolates from CRC patients}

Antimicrobial resistance of the $33 C$. difficile isolates was tested against 12 antibiotics. All the isolates were susceptible to vancomycin and metronidazole. Only one isolate was resistant to piperacillin-tazobactam. The relationship of antimicrobial resistance of the C. difficile isolates and clinical characteristics of CRC patients were analyzed. As shown in Table 2, patients of rectum cancer bore more fusidic acid resistant $C$. difficile isolates than those of colon cancer (OR: 7.15, 95\% CI: 1.53-33.37, $P=0.01$ ). In addition, CRC patients over 60 years old carried more moxifloxacin susceptible isolates than patients less than 60 years old (OR: 7.00, 95\%CI: 1.17-41.76, $P=0.02$ ). Antibiotic resistance profiles were also correlated with MLST relationships. All ST35 isolates and all but one ST37 isolates were resistant to tetracycline. All ST 37 isolates were resistant to clindamycin. All but one ST35 isolates were resistant to erythromycin (data not shown). Notably, the only one non-toxigenic isolate, ST15, was resistant to tetracycline only, but susceptible to all other antibiotics. It implies that the non-toxigenic $C$. difficile isolate had a lower level of antibiotics resistance than toxigenic $C$. difficile isolate.

\section{DISCUSSION}

CRC is among the most commonly diagnosed malignancy all over the world [20]. Apart from the life style and pre-existed comorbidities such as ulcerative colitis and adenomas, alteration in gut microbiota is regarded as an important driving factor during the carcinogenesis of CRC. According to previous reports, $F$. nucleatum, enterotoxigenic $B$. fragilis and adherentinvasive $E$. coli are all found to promote the adenomacarcinoma sequence [21-24].

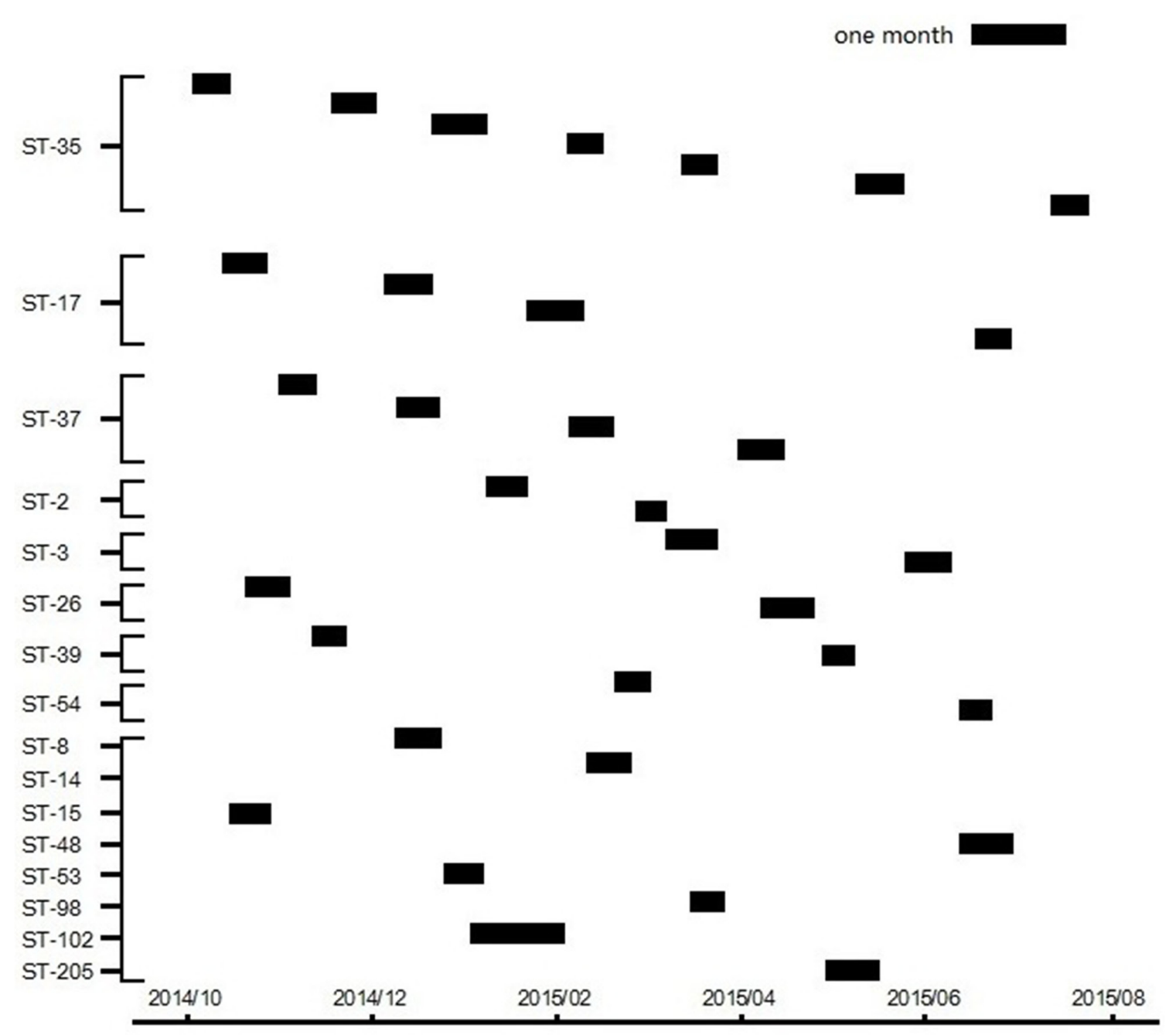

Figure 2: Time-space cluster map of different STs from individual CRC patients with $C$. difficile colonization. Y-axis depicts unique multilocus STs. X-axis (bottom) shows the duration of the study period. Each small box represents the date of admission and the length of hospital stay of an individual $C$. difficile colonizing CRC patient. 
Table 2: Antibiotic resistance profile of 33 C. difficile strains according to pathology and demographic characteristics

\begin{tabular}{|c|c|c|c|c|c|c|c|}
\hline \multirow[t]{4}{*}{ Antibiotic } & \multicolumn{7}{|c|}{ No. (\%) resistant } \\
\hline & \multirow{3}{*}{$\begin{array}{l}\text { Total } \\
\mathbf{n}=\mathbf{3 3}\end{array}$} & \multicolumn{3}{|c|}{ Cancer site } & \multicolumn{3}{|c|}{ Age } \\
\hline & & Rectum & Colon & $P$ value & $<60$ & $\geq 60$ & $P$ value \\
\hline & & $n=18$ & $n=15$ & & $\mathrm{n}=\mathbf{9}$ & $n=24$ & \\
\hline Fusidic acid & $17(51.5)$ & $13(72.2)$ & $4(26.7)$ & $0.01^{*}$ & $4(44.4)$ & $13(54.2)$ & 0.62 \\
\hline Ciprofloxacin & $26(78.8)$ & $14(77.8)$ & $12(80.0)$ & 0.88 & $9(100.0)$ & $17(70.8)$ & 0.07 \\
\hline $\begin{array}{l}\text { Piperacillin/ } \\
\text { Tazobactam }\end{array}$ & $1(3.0)$ & $1(5.6)$ & $0(0)$ & NA & $0(0)$ & $1(4.2)$ & NA \\
\hline Metronidazole & $0(0)$ & $0(0)$ & $0(0)$ & NA & $0(0)$ & $0(0)$ & NA \\
\hline Rifampicin & $9(27.3)$ & $5(27.8)$ & $4(26.7)$ & 0.94 & $1(11.1)$ & $8(33.3)$ & 0.20 \\
\hline Moxifloxacin & $15(45.5)$ & $6(33.3)$ & $9(60.0)$ & 0.13 & $7(77.8)$ & $8(33.3)$ & $0.02^{*}$ \\
\hline Gatifloxacin & $14(42.4)$ & $8(44.4)$ & $6(40.0)$ & 0.80 & $2(22.2)$ & $12(50.0)$ & 0.15 \\
\hline Vancomycin & $0(0)$ & $0(0)$ & $0(0)$ & NA & $0(0)$ & $0(0)$ & NA \\
\hline Clindamycin & $21(63.6)$ & $12(66.7)$ & $9(60.0)$ & 0.69 & $6(66.7)$ & $15(62.5)$ & 0.83 \\
\hline Levofloxacin & $22(66.7)$ & $12(66.7)$ & $10(66.7)$ & 1.00 & $7(77.8)$ & $15(62.5)$ & 0.41 \\
\hline Tetracycline & $16(48.5)$ & $8(44.4)$ & $8(53.3)$ & 0.53 & $6(66.7)$ & $10(41.7)$ & 0.20 \\
\hline Erythromycin & $21(63.6)$ & $11(61.1)$ & $10(66.7)$ & 0.74 & $8(88.9)$ & $13(54.2)$ & 0.07 \\
\hline
\end{tabular}

${ }^{*} P<0.05$

So far the exact colonization pattern of $C$. difficile in CRC patients has not been determined yet. In a prospective study, $19 \%$ of patients were colonized with toxigenic $C$. difficile on admission to oncology [25]. The rate of $C$. difficile colonization in admitted children in hematologic ward was reported to be $25.6 \%$, with a $92.6 \%$ of toxigenic strains [10]. Our previous study revealed a $20.5 \%$ of toxigenic $C$. difficile colonization in cancer patients [9]. No symptomatic CDI patients were revealed in our study although the prevalence of $C$. difficile colonization in preoperative CRC patients was high in China from our clinical experience. We speculated that antiemetic pharmaceuticals might inhibit patients' diarrhea symptoms to some extent in the course of ongoing treatment. Furthermore, CDI clinical severity is generally mild to moderate in Chinese patients in our other studies [26]. However, the data remain scanty. Even though CDI has been prevalent in $15 \%$ of cancer patients receiving chemotherapy [27], the relationship between $C$. difficile colonization and CDI in cancer patients remains unclear. Further investigations are needed to clarify the risk factors triggering the transformation from $C$. difficile colonization to $\mathrm{CDI}$ in cancer patients.

Stage T4 and LN metastasis are both high risk factors for recurrence and indications for adjuvant chemotherapy in CRC patients. Our results indicated that CRC patients with more advanced disease (T4 or LN metastasis) who definitely need adjuvant chemotherapy after surgery tend to have higher rate of $C$. difficile colonization. It is accepted that the colonization of $C$. difficile in large intestine is prevented by the barrier of the gut microbiota. Weakening of this resistance by cancer is the major risky condition leading to infection. Differences in colon microbiota between individuals with a normal colonoscopy and $\mathrm{CRC}$ have been reported [28, 29]. In addition, relatively longer disease course and more aggressive treatment in patients with stage $\mathrm{T} 4$ and LN metastasis could compromise the protection of gut microbiota and facilitate $C$. difficile colonization. From the pathological perspective, changes in the composition of the gut microbiota may lead to the instability of homeostasis, resulting inflammation, dysplasia, and carcinogenesis [30-32]. Presence and overgrown of $C$. difficile in CRC patients, especially during the adjuvant chemotherapy, might develop CDI and result in severe diarrhea, which in turn halts the ongoing chemotherapy [33]. Therefore, C. difficile colonization should be examined for all preoperativeCRC patients as a part of risk stratification for further cancer therapy.

There were no clear correlation between the rate of $C$. difficile colonization and the sites of origin, histological morphology, and metabolic factors of the cancer. Although a previous study demonstrated a predictable role of albumin in CDI [34], none of the metabolic factors described here seems to be capable to predict $C$. difficile colonization in CRC patients. However, we notably found $\mathrm{OB}$ negative patients 
had a higher rate of $C$. difficile colonization. Previous studies also disclosed that there are extremely few CDI patients with positive fecal OB [35]. The possible reason underlying this finding is that bleeding from the cancer lesions might change microbiota and microenvironment, leading to the alteration of $C$. difficile colonization. Moreover, blood components might also hinder $C$. difficile colonization or CDI. More studies are needed in order to clarify the relationship between $\mathrm{OB}$ and $C$. difficile colonization

There was a specific correlation between antibiotic resistance and clinical characteristics, indicating that the individualized therapeutic scheme should be considered according to clinical characteristics of the patients. All the isolates in this study were susceptible to metronidazole and vancomycin with low minimal inhibitory concentration. Besides, the resistant rate to piperacillintazobactam is relatively low, which suggests it can serve as an alternative option for treatment of CDI in CRC patients. The non-toxigenic isolate was resistant only to tetracycline, indicating a significant narrower antibiotic resistance in the non-toxigenic isolates than that in the toxigenic isolates.

Compared with hospital-acquired infection, morbidity and mortality associated with communityacquired $C$. difficile colonization are lower [36]. All the cases in this study were genetically and epidemiologically unrelated to one another based on MLST analysis and epidemiological data. We also investigated the molecular typing of $C$. difficile from same patients 48 hours after admission. The results showed the molecular spectrum of $C$. difficile isolates was still wide (data not shown), suggesting these patients were community-acquired according to the 2010 SHEA/IDSA guideline [7]. The findings can be possibly used as reliable data for further investigation of the $C$. difficile transmission pattern in China.

In conclusion, this is a preliminary study in determining prevalence and revealing risk factors of $C$. difficile colonization in CRC patients in China. CRC patients harboring high risk factors such as T4 or LN metastasis tended to have higher $C$. difficile colonization rate. Therefore, peri-operative screening and monitoring for $C$. difficile is of great importance in these patients in order to avoid discontinuation of chemotherapy due to severe diarrhea and postoperative complications. Besides, OB negativity increases risk of $C$. difficile colonization in CRC patient. As high as $97.0 \%$ of colonized $C$. difficile strains were toxigenic with multiple antibiotics resistance. $C$. difficile colonization may not be mainly acquired in hospitals due to the absence of epidemiologic relatedness in preoperative CRC patients. A larger-population-based study and mechanism-specific research is needed in the future in order to clarify the exact role of $C$. difficile colonization in CRC patients.

\section{MATERIALS AND METHODS}

\section{Design of the study}

Stool samples were collected from consecutive preoperative CRC patients who were scheduled to accept radical cancer resection in Department of Colorectal Surgery, the First Affiliated Hospital of Zhejiang University. The study protocol was approved by the Institutional Ethics Committees of the hospital and the study was performed in accordance with the guidelines recommended by National Institute of Health involving human subjects and animal care and 1975 Declaration of Helsinki. All patients provided written consent. Stool samples within 24 hours of admission were collected from each patient, and delivered to Department of Microbiology, Zhejiang Provincial Center for Disease Control and Prevention for culture, identification of toxin gene and antibiotic susceptibility testing.

\section{Patients}

The study was performed between October, 2014 and August, 2015. All CRC patients were to undergo surgical resection after stool sample collection, with no preoperative chemotherapy received. No notable longterm diarrhea was reported by the patients. No antibiotics were used prior to the stool sample collection. Re-admitted patients were excluded. Demographic information and pathological findings collected from the patients include age, gender, body mass index, cancer stages ( $T$ stage: Depth of primary cancer infiltration; $\mathrm{N}$ stage: Regional lymph nodes metastasis), cancer differentiation, and sites of origin. Laboratory results such as blood hemoglobin level, stool occult blood (OB), fasting blood glucose, serum albumin, triglyceride, total cholesterol, and high density lipoprotein were also included.

\section{Stool culture and $C$. difficile isolation}

C. difficile isolation from the stool collected within 24 hours of admission was processed as the follows. Specimens were firstly treated with alcohol. The mixture was then inoculated into cefoxitin-cycloserine fructose agar (CCFA) plates (UK Bio, Hangzhou, China). After incubation for 48 hours at $37^{\circ} \mathrm{C}$ in a GENbag anaerobic chamber (BioMérieux, Marcy l'Etoile, France), up to ten suspected colonies for each stool specimen were analyzed and confirmed to be $C$. difficile as described by Loo et al [37]. The $C$. difficile isolates were stored within the blood broth in a preservation kit (UKbio, Hangzhou) at $-80^{\circ} \mathrm{C}$.

\section{Identification of toxin gene and bioinformatics}

All bacterial colonies for each stool specimen were identified. Bacterial genomic DNAs were extracted using 
DNeasy Blood \& Tissue kit (QIAGEN, Inc., Valencia, CA) according to the manufacturer's instructions. A multiplex real time PCR assay provided by the UK Bio company in Hangzhou was used for detection of the two toxin genes ( $t c d \mathrm{~A}$ and $t c d \mathrm{~B})$ in order to determine between non-toxigenic and toxigenic isolates. Seven housekeeping genes $(a d k, a t p \mathrm{~A}, d x r, g l y \mathrm{~A}, \operatorname{rec} \mathrm{A}, \operatorname{sod} \mathrm{A}$, and $t p i$ ) selected based on a previous study by Griffiths et al. were used for multilocus sequence typing (MLST) [38]. After the standard procedure of PCR, the amplified products were sequenced. Data was uploaded into a public C. difficile MLST database, accessible at http://pubmlst. org/cdifficile, for determining sequence types (ST). The eBURST was used to identify clonal complexes, each of those are defined by one of the seven typed genes, which bear different features from one another. Minimum spanning tree that reveals the allelic difference between isolates of the seven housekeeping genes was constructed by application of Bionumerics software (Applied Math). The Simpson's index of diversity (D value) was calculated with an in-house program, MLEECOMP package.

\section{Antibiotic susceptibility testing}

In vitro testing for susceptibilities of antibiotics including fusidic acid, ciprofloxacin, levofloxacin, moxifloxacin, gatifloxacin, piperacillin-tazobactam, rifampicin, clindamycin, erythromycin, tetracycline, metronidazole and vancomycin was carried out using an E-test assay according to the supplement from Clinical and Laboratory Standards Institute (CLSI)[39]. Six E-test strips (BioMérieux, Marcy l'Etoile, France) were tested in one plate with brucella broth agar. Results were analyzed and categorized as susceptible, intermediate or resistant according to the CLSI breakpoints and other previous studies [39-41].

\section{Statistical analysis}

Statistical analysis was performed by applying SPSS 20.0 (Chicago, IL, USA). Categorized data were analyzed with the chi-squared test. The F-test and T-test were conducted for hetero or equal variance analysis. Significance of characteristics in individual patients was determined by multivariate logistic regression analysis. Statistical significance for all tests was defined as $P<0.05$.

\section{ACKNOWLEDGMENTS}

The authors thank Dr. Elaine Cheong and Dr. Gang Cheng from Sydney hospital for critically reviewing the manuscript.

\section{CONFLICTS OF INTEREST}

The authors declare no conflicts of interest.

\section{FUNDING}

This work was supported by grants from Natural Science Foundation of Zhejiang Province (LQ14H160009), Major Scientific Project of Zhejiang (2016C03G1121060), and grants from National Natural Science Foundation of China (81472210 and 81471998). This work was also supported by the Key Research and Development Program of Zhejiang (2015G03048), the Program for Major Science and Technology Medicine and Healthcare in Zhejiang (WKJ-ZJ-1507), and the Zhejiang Key Subject of Clinical Medical Engineering (G3221).

\section{Author's contributions}

Y.Z., Y.L., C.H., and X.J.S. carried out the bacterial and molecular experiments and analyzed the results. Y.Z. and Y.L. discussed and wrote the manuscript. Y.X.L., Q.S.S., J.Y., W.B.C., and J.J.L. collected the stool samples, P.Z., W.Q.J., L.L.L. and Z.T. collected clinical and pathological information from the cancer patients, Y.W.T., D.Z.J., and W.J.F. designed the study, guided data analysis and interpretation and revised the manuscript critically for important intellectual content. All authors reviewed the manuscript.

\section{REFERENCES}

1. Lessa FC, Mu Y, Bamberg WM, Beldavs ZG, Dumyati GK, Dunn JR, Farley MM, Holzbauer SM, Meek J, Phipps EC, Wilson LE, Winston LG, Cohen JA, et al. Burden of Clostridium difficile infection in the United States. N Engl J Med. 2015; 372: 825-34. doi: 10.1056/NEJMoa1408913.

2. Kuijper EJ, van Dissel JT. Spectrum of Clostridium difficile infections outside health care facilities. CMAJ. 2008; 179: 747-8. doi: 10.1503/cmaj.081211.

3. Garey KW, Dao-Tran TK, Jiang ZD, Price MP, Gentry LO, Dupont HL. A clinical risk index for Clostridium difficile infection in hospitalised patients receiving broad-spectrum antibiotics. J Hosp Infect. 2008; 70: 142-7. doi: 10.1016/j. jhin.2008.06.026.

4. Biagi E, Nylund L, Candela M, Ostan R, Bucci L, Pini E, Nikkila J, Monti D, Satokari R, Franceschi C, Brigidi P, De Vos W. Through ageing, and beyond: gut microbiota and inflammatory status in seniors and centenarians. PLoS One. 2010; 5: e10667. doi: 10.1371/journal.pone.0010667.

5. DuPont HL. The search for effective treatment of Clostridium difficile infection. N Engl J Med. 2011; 364: 473-5. doi: 10.1056/NEJMe1013236.

6. Chopra T, Alangaden GJ, Chandrasekar P. Clostridium difficile infection in cancer patients and hematopoietic stem cell transplant recipients. Expert Rev Anti Infect Ther. 2010; 8: 1113-9. doi: 10.1586/eri.10.95.

7. Cohen SH, Gerding DN, Johnson S, Kelly CP, Loo VG, McDonald LC, Pepin J, Wilcox MH, Society for 
Healthcare Epidemiology of A, Infectious Diseases Society of A. Clinical practice guidelines for Clostridium difficile infection in adults: 2010 update by the society for healthcare epidemiology of America (SHEA) and the infectious diseases society of America (IDSA). Infect Control Hosp Epidemiol. 2010; 31: 431-55. doi: 10.1086/651706.

8. Zhang X, Wang X, Yang J, Liu X, Cai L, Zong Z. Colonization of toxigenic Clostridium difficile among ICU patients: a prospective study. BMC Infect Dis. 2016; 16: 397. doi: 10.1186/s12879-016-1729-2.

9. Fang WJ, Jing DZ, Luo Y, Fu CY, Zhao P, Qian J, Tian BR, Chen XG, Zheng YL, Zheng Y, Deng J, Zou WH, Feng XR, et al. Clostridium difficile carriage in hospitalized cancer patients: a prospective investigation in eastern China. BMC Infect Dis. 2014; 14: 523. doi: 10.1186/1471-2334-14-523.

10. Armin S, Shamsian S, Drakhshanfar H. Colonization with Clostridium difficile in Children with Cancer. Iran J Pediatr. 2013; 23: 473-6.

11. Bruminhent J, Wang ZX, Hu C, Wagner J, Sunday R, Bobik B, Hegarty S, Keith S, Alpdogan S, Carabasi M, FilickoO'Hara J, Flomenberg N, Kasner M, et al. Clostridium difficile colonization and disease in patients undergoing hematopoietic stem cell transplantation. Biol Blood Marrow Transplant. 2014; 20: 1329-34. doi: 10.1016/j. bbmt.2014.04.026.

12. Jain T, Croswell C, Urday-Cornejo V, Awali R, Cutright J, Salimnia H, Reddy Banavasi HV, Liubakka A, Lephart P, Chopra T, Revankar SG, Chandrasekar P, Alangaden G. Clostridium Difficile Colonization in Hematopoietic Stem Cell Transplant Recipients: A Prospective Study of the Epidemiology and Outcomes Involving Toxigenic and Nontoxigenic Strains. Biol Blood Marrow Transplant. 2016; 22: 157-63. doi: 10.1016/j.bbmt.2015.07.020.

13. Ziakas PD, Zacharioudakis IM, Zervou FN, Grigoras C, Pliakos EE, Mylonakis E. Asymptomatic carriers of toxigenic C. difficile in long-term care facilities: a metaanalysis of prevalence and risk factors. PLoS One. 2015; 10: e0117195. doi: 10.1371/journal.pone.0117195.

14. Galdys AL, Nelson JS, Shutt KA, Schlackman JL, Pakstis DL, Pasculle AW, Marsh JW, Harrison LH, Curry SR. Prevalence and duration of asymptomatic Clostridium difficile carriage among healthy subjects in Pittsburgh, Pennsylvania. J Clin Microbiol. 2014; 52: 2406-9. doi: 10.1128/jcm.00222-14.

15. Hung YP, Lee JC, Lin HJ, Liu HC, Wu YH, Tsai PJ, Ko WC. Clinical impact of Clostridium difficile colonization. J Microbiol Immunol Infect. 2015; 48: 241-8. doi: 10.1016/j. jmii.2014.04.011.

16. Galdys AL, Curry SR, Harrison LH. Asymptomatic Clostridium difficile colonization as a reservoir for Clostridium difficile infection. Expert Rev Anti Infect Ther. 2014; 12: 967-80. doi: 10.1586/14787210.2014.920252.

17. Loo VG, Bourgault AM, Poirier L, Lamothe F, Michaud $\mathrm{S}$, Turgeon N, Toye B, Beaudoin A, Frost EH, Gilca R, Brassard P, Dendukuri N, Beliveau C, et al. Host and pathogen factors for Clostridium difficile infection and colonization. N Engl J Med. 2011; 365: 1693-703. doi: 10.1056/NEJMoa1012413.

18. Jump RL, Pultz MJ, Donskey CJ. Vegetative Clostridium difficile survives in room air on moist surfaces and in gastric contents with reduced acidity: a potential mechanism to explain the association between proton pump inhibitors and C. difficile-associated diarrhea? Antimicrob Agents Chemother. 2007; 51: 2883-7. doi: 10.1128/aac.01443-06.

19. Feng Q, Liang S, Jia H, Stadlmayr A, Tang L, Lan Z, Zhang D, Xia H, Xu X, Jie Z, Su L, Li X, Li X, et al. Gut microbiome development along the colorectal adenomacarcinoma sequence. Nat Commun. 2015; 6: 6528. doi: $10.1038 /$ ncomms 7528 .

20. Siegel RL, Miller KD, Jemal A. Cancer statistics, 2015. CA Cancer J Clin. 2015; 65: 5-29. doi: 10.3322/caac.21254.

21. Kostic AD, Chun E, Robertson L, Glickman JN, Gallini CA, Michaud M, Clancy TE, Chung DC, Lochhead P, Hold GL, El-Omar EM, Brenner D, Fuchs CS, et al. Fusobacterium nucleatum potentiates intestinal tumorigenesis and modulates the tumor-immune microenvironment. Cell Host Microbe. 2013; 14: 207-15. doi: 10.1016/j. chom.2013.07.007.

22. Huang $\mathrm{H}$, Wu S, Wang M, Zhang Y, Fang H, Palmgren AC, Weintraub A, Nord CE. Clostridium difficile infections in a Shanghai hospital: antimicrobial resistance, toxin profiles and ribotypes. Int J Antimicrob Agents. 2009; 33: 339-42. doi: 10.1016/j.ijantimicag.2008.09.022.

23. Arthur JC, Perez-Chanona E, Muhlbauer M, Tomkovich S, Uronis JM, Fan TJ, Campbell BJ, Abujamel T, Dogan B, Rogers AB, Rhodes JM, Stintzi A, Simpson KW, et al. Intestinal inflammation targets cancer-inducing activity of the microbiota. Science. 2012; 338: 120-3. doi: 10.1126/ science. 1224820 .

24. Arthur JC, Gharaibeh RZ, Muhlbauer M, Perez-Chanona E, Uronis JM, McCafferty J, Fodor AA, Jobin C. Microbial genomic analysis reveals the essential role of inflammation in bacteria-induced colorectal cancer. Nat Commun. 2014; 5: 4724. doi: 10.1038/ncomms5724.

25. Burgner D, Siarakas S, Eagles G, McCarthy A, Bradbury $\mathrm{R}$, Stevens M. A prospective study of Clostridium difficile infection and colonization in pediatric oncology patients. Pediatr Infect Dis J. 1997; 16: 1131-4.

26. Jin D, Luo Y, Huang C, Cai J, Ye J, Zheng Y, Wang L, Zhao P, Liu A, Fang W, Wang X, Xia S, Jiang J, et al. Molecular Epidemiology of Clostridium difficile Infection in Hospitalized Patients in Eastern China. J Clin Microbiol. 2016. doi: 10.1128/jcm.01898-16.

27. Han XH, Du CX, Zhang CL, Zheng CL, Wang L, Li D, Feng Y, DuPont HL, Jiang ZD, Shi YK. Clostridium difficile infection in hospitalized cancer patients in Beijing, China is facilitated by receipt of cancer chemotherapy. Anaerobe. 2013; 24: 82-4. doi: 10.1016/j. anaerobe.2013.05.004. 
28. Sobhani I, Tap J, Roudot-Thoraval F, Roperch JP, Letulle S, Langella P, Corthier G, Tran Van Nhieu J, Furet JP. Microbial dysbiosis in colorectal cancer (CRC) patients. PLoS One. 2011; 6: e16393. doi: 10.1371/journal.pone.0016393.

29. Amiot A, Mansour H, Baumgaertner I, Delchier JC, Tournigand C, Furet JP, Carrau JP, Canoui-Poitrine F, Sobhani I. The detection of the methylated Wif-1 gene is more accurate than a fecal occult blood test for colorectal cancer screening. PLoS One. 2014; 9: e99233. doi: 10.1371/ journal.pone.0099233.

30. Abreu MT, Peek RM, Jr. Gastrointestinal malignancy and the microbiome. Gastroenterology. 2014; 146: 1534-46 e3. doi: 10.1053/j.gastro.2014.01.001.

31. Candela M, Turroni S, Biagi E, Carbonero F, Rampelli $\mathrm{S}$, Fiorentini C, Brigidi P. Inflammation and colorectal cancer, when microbiota-host mutualism breaks. World J Gastroenterol. 2014; 20: 908-22. doi: 10.3748/wjg.v20.i4.908.

32. Gao Z, Guo B, Gao R, Zhu Q, Qin H. Microbiota disbiosis is associated with colorectal cancer. Front Microbiol. 2015; 6: 20. doi: 10.3389/fmicb.2015.00020.

33. Ryder AB, Huang Y, Li H, Zheng M, Wang X, Stratton $\mathrm{CW}, \mathrm{Xu} \mathrm{X}$, Tang YW. Assessment of Clostridium difficile infections by quantitative detection of tcdB toxin by use of a real-time cell analysis system. J Clin Microbiol. 2010; 48: 4129-34. doi: 10.1128/JCM.01104-10.

34. Khanafer N, Barbut F, Eckert C, Perraud M, Demont C, Luxemburger C, Vanhems P. Factors predictive of severe Clostridium difficile infection depend on the definition used. Anaerobe. 2016; 37: 43-8. doi: 10.1016/j. anaerobe.2015.08.002.

35. Morimoto Y, Nomura K, Tsutsumi Y, Ohshiro M, Fujimoto Y, Shimizu D, Wakabayashi N, Konishi H, Mitsufuji S,
Matsumoto Y, Taniwaki M. Clostridium difficile-associated diarrhea with hematochezia is associated with ulcer formation. Scand J Gastroenterol. 2008; 43: 967-70.

36. Leffler DA, Lamont JT. Clostridium difficile infection. $N$ Engl J Med. 2015; 372: 1539-48. doi: 10.1056/ NEJMra1403772.

37. Loo VG, Poirier L, Miller MA, Oughton M, Libman MD, Michaud S, Bourgault AM, Nguyen T, Frenette C, Kelly M, Vibien A, Brassard P, Fenn S, et al. A predominantly clonal multi-institutional outbreak of Clostridium difficile-associated diarrhea with high morbidity and mortality. N Engl J Med. 2005; 353: 2442-9. doi: 10.1056/ NEJMoa051639.

38. Griffiths D, Fawley W, Kachrimanidou M, Bowden R, Crook DW, Fung R, Golubchik T, Harding RM, Jeffery KJ, Jolley KA, Kirton R, Peto TE, Rees G, et al. Multilocus sequence typing of Clostridium difficile. J Clin Microbiol. 2010; 48: 770-8. doi: 10.1128/JCM.01796-09.

39. CLSI. (2014). performance Standards for Antimicrobial susceptibility Testing;Twenty-Fourth Informational Supplement. CLSI M100-S24.

40. Bourgault AM, Lamothe F, Loo VG, Poirier L, Group C-CS. In vitro susceptibility of Clostridium difficile clinical isolates from a multi-institutional outbreak in Southern Quebec, Canada. Antimicrob Agents Chemother. 2006; 50: 3473-5. doi: 10.1128/AAC.00479-06.

41. Mutlu E, Wroe AJ, Sanchez-Hurtado K, Brazier JS, Poxton IR. Molecular characterization and antimicrobial susceptibility patterns of Clostridium difficile strains isolated from hospitals in south-east Scotland. J Med Microbiol. 2007; 56: 921-9. doi: 10.1099/jmm.0.47176-0. 